\title{
AL 5083 Alüminyum Malzemeye Vida Açma İşleminde Kılavuz Geometrisi Etkisinin İncelenmesi
}

\author{
Hüseyin GÖKÇE*a®i
}

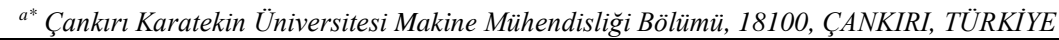

\begin{tabular}{l} 
MAKALE \\
BİLGISI \\
\hline Alınma: 19.11 .2020 \\
Kabul: 20.12 .2020 \\
\hline Anahtar Kelimeler: \\
Alüminyum \\
Vida açma \\
Kılavuz geometrisi \\
Vida geometrisi \\
"sorumlu Yazar: \\
e-posta: \\
huseyingokce@karate \\
kin.edu.tr
\end{tabular}

\begin{abstract}
ÖZET
Bu çalı̧̧mada balistik özellikleri ve yüksek korozyon direnç ile karakterize edilen Al 5083 H116 malzemesine HSS kılavuz takımlarla vida açma işlemi uygulanmıştır. Oluşturulan vida dişleri ile teorik olarak hesaplanan standart vida dişlerine ait diş dibi ve diş üstü ölçüleri arasındaki farklar kesme hızı ve kılavuz geometrisi açılarından incelenmiştir. Deneyler 2, 4 ve $8 \mathrm{~m} / \mathrm{dk}$. kesme hızları ile kuru şartlarda yapılmıştır. Oluşturulan vidalar eksenleri doğrultusunda tel erezyon tezgâhında kesilmiş ve elde edilen kesitler optik mikroskop ile görüntülenmiştir. Bu görüntüler bilgisayar destekli tasarım programına aktarılarak gerekli ölçümler yapılmıştır. Ölçümler sonucunda Al 5083 H116 alüminyum alaşımına diş açılmasında helis açısına sahip kılavuzların kullanılması diş profillerinin nispeten daha düzgün çıkmasına ve standart değerlere en yakın sonuçlar elde edilmesine olanak sağladığı görülmüştür.
\end{abstract}

\section{Investigation of The Effect of The Tap Geometry on The Al 5083 Aluminium Material in Tapping}

\author{
ARTICLE \\ INFO \\ Received: 19.11 .2020 \\ Accepted: 20.12 .2020

Keywords:
Aluminium
tapping
tap geometry
thread geometry
${ }^{* \text { Corresponding }}$
Authors
e-mail:
huseyingokce@karate
kin.edu.tr

\section{GIRISŞ (INTRODUCTION)}

Düşük yoğunluk ve mekanik özellikler sergileyen saf alüminyum, alaşım elementleri ilave edilmesi ve/veya 1 sıl işlem yöntemleri ile kimyasal ve mekanik özelliklerinde önemli artışlar göstermektedir. Düşük yoğunluğuna rağmen yüksek mekanik özellikler

\begin{abstract}
In this study, threading process with HSS taps was applied to Al $5083 \mathrm{H} 116$ aluminium alloy, which is characterized by its ballistic properties and high corrosion resistance. Differences between screw crest and root dimensions, of the standard screw with calculated theoretically screw with the threads was examined in terms of cutting speed and tap geometry. The experiments were carried out in dry conditions with cutting speeds of 2, 4 and $8 \mathrm{~m} / \mathrm{min}$. The screws formed were cut in the direction of their axes on the electrical discharge machine and the sections obtained were viewed with an optical microscope. These images were transferred to the computer-aided design program and necessary measurements were made. As a result of the measurements, it has been observed that the use of helix angle taps in tapping Al 5083 H116 aluminium alloy enables the screw profiles to appear relatively smooth and to obtain results closest to the standard values.
\end{abstract}

https://dx.doi.org/10.30855/gmbd.2020.03.07

Bu makaleye atıf yapmak için: H. Gökçe, "AL 5083 Alüminyum Malzemeye Vida Açma İşleminde Kılavuz Geometrisi Etkisinin İncelenmesi,” Gazi Mühendislik Bilimleri Dergisi, cilt 6, sayı 3, s. 242-247, Aralık, 2020, doi: https://dx.doi.org/10.30855/gmbd.2020.03.07. 
Talaşlı imalat işlemlerinden olan kılavuzla vida açma diğer talaşlı imalat operasyonlarına kıyasla daha karmaşı bir işlemdir. Vida profillerinin ve yüzeylerinin arzulanan toleranslar dâhilinde olması cıvata ve somun bağlantısının doğru ve istenilen kalitede olması için oldukça önem arz etmektedir [57]. Toplam işlenebilir zamanının yaklaşık \%22'sini alan vida açma operasyonunda kılavuz geometrisinin ve kesme şartlarının doğru belirlenmesi verimlilik açısından da dikkate alınması gereken önemli unsurlardandır $[8,9]$.

Uzun ve Korkut, Ti6Al4V titanyum malzeme üzerine kriyojenik işlem görmüş ve görmemiş bir dizi kılavuz ile sslak ve kuru şartlarda vida açma deneyleri yapmışlardır. Deneyler sonucunda kesme kuvveti ve torkunun kriyojenik işlem görmüş kılavuzlarda düşme eğilimine girdiğini belirtmişlerdir [5]. Nalbant vd. AISI 1050 malzemesi ile kesme hızını sabit tutarak kılavuz giriş açılarındaki değişimlerin kesme kuvvetleri üzerindeki etkilerini incelemişlerdir. Özellikle radyal kuvvetlerin enerji tüketiminde önemli rol oynadıklarını ve ayrıca optimum giriş açısının $30^{\circ}$ olduğunu ifade etmişlerdir [6]. Günay yaptığ 1 çalışmada vida açma sürecinde oluşan kuvvetleri ve yüzey pürüzlülüklerini incelemiştir. Bileşke kesme kuvvetlerinin radyal yüklerden önemli ölçüde etkilendiğini belirtmiştir. Oluşturduğu vida profilleri üzerinde gerçekleştirdiği mikro sertlik ölçümleri neticesinde diş üstünden diş dibine doğru sertlik değerinde artış olduğunu açıklamıştır [7]. Kayır, 5083 alüminyum alaşımı üzerine farklı matkap çapları ile delinmiş deliklere farklı kaplamalara sahip HSS kılavuzlar ile vida açma işlemi uygulamıştır. Matkap çaplarındaki değişimin kesme kuvvelerini doğrudan etkilediğini ifade etmiştir [9]. Uzun ve Korkut, vida açma işleminde kılavuz kullanımının malzeme cinsi, kılavuz geometrisi, kılavuz çekme metodu, delik tipi ve ölçüleri gibi başlıca faktörlerden etkilendiğini belirtmişlerdir [10]. Gökçe ve Yavuz yaptıkları çalışmada işlenmesi zor olan molibden malzemeye değişen kesme hızlarında bir dizi kılavuz çekme deneyi yapmışlardır. Deney sonuçlarını oluşturdukları diş profillerine ait diş üstü ve diş dibi ölçüleri açılarından mukayese etmişlerdir. Nispeten düşük kesme hızlarında dişlerde kırılmalar ve diş profillerinin bozulduğunu gözlemlemişler, optimum kesme hızının $9 \mathrm{~m} / \mathrm{dk}$. olduğunu vurgulamışlardır [11]. Reiter vd. östenitik paslanmaz çeliklere açılmış kör deliklerde PVD TiCN kaplamalı kılavuzların etkilerini incelemişlerdir. Kaplamanın aşınma direncini önemli ölçüde artırdığını ve böylece takım ömrü üzerinde etkili oluğunu ifade etmişlerdir [12]. Jin vd. Ti15V3Cr3Mo3Al titanyum alaşımında CBN kaplamalı kılavuzun etkilerini incelemişlerdir. CBN kaplamanın vida tamlı̆̆ı, kesme torku ve takım ömrü üzerinde olumlu açıdan etkili olduğunu belirtmişlerdir [13].

Literatür taraması neticesinde, özellikle yüksek mukavemetli bir alüminyum alaşımı olan A15083 H114 alaşımı için diş profillerinin temel tanımlamalarından olan diş üstü (DÜ) ve diş dibi (DD) gibi ölçümlerin yeterli düzeyde incelenmediği görülmüştür. Bu amaçla çalışmada, 2 farklı değişken içeren ( 3 farklı kesme hızı ve 3 farklı HSS kılavuz geometrisi) tam faktöriyel deney tasarımı ile kesme sıvısı kullanılmaksızın kılavuzla vida açma deneyleri yapılmıştır. Deney sonuçları oluşturulan vida profillerine ait DÜ ve DD ölçümleri ile değerlendirilmiştir.

\section{MATERYAL VE METOT (MATERIAL AND METHOD)}

Tablo 1'de bazı özellikleri verilen $\varnothing 60 \times 18 \mathrm{~mm}$ ölçülerindeki Al 5083 H116 deney malzemesine M8 $\times 1,25$ standart vida dişlerinin açılabilmesi için Ø6,8 matkap ile Şekil 1'de gösterilen koordinatlarda boydan boya delikler delinmiştir. Deney malzemesi, CNC dik işleme merkezi tablasına 4 ayakı ıir ayna ile bağlanmış ve parça sökülmeksizin delik delme ve kılavuz çekme işlemleri gerçekleştirilmiş̧ir. Deneyler tam faktöriyel deney tasarımına uygun olarak Tablo 2'de verilen kılavuz çekme parametreleri ve değerleriyle yapılmıştır. Kılavuz takımlar takım tutucuya $30 \mathrm{~mm}$ taşma uzunluğunda ve pens marifetiyle bağlanmışlardır. Kılavuzlara ait teknik özellikler Tablo 3'te verilmiştir.

Tablo 1. Al 5083 H1 16 alaşımının bazı özellikleri

[14] (Some properties of Al 5083 H116 alloy)

\begin{tabular}{|c|c|c|}
\hline Özellik & Birim & Al 5083 H116 \\
\hline Yoğunluk $\left(20^{\circ} \mathrm{C}\right)$ & $\mathrm{g} / \mathrm{cm}^{3}$ & 2,66 \\
\hline Erime sıcaklığ 1 & ${ }^{\circ} \mathrm{C}$ & $590,6-638$ \\
\hline Brinell sertlik değeri & $\mathrm{HB}$ & 85 \\
\hline Akma gerilmesi & $\mathrm{MPa}$ & 228 \\
\hline Çekme gerilmesi & $\mathrm{Mpa}$ & 317 \\
\hline Elastikiyet modülü & $\mathrm{GPa}$ & 71 \\
\hline Poisson oranı & - & 0,33 \\
\hline Isı transfer katsayısı $\left(20^{\circ} \mathrm{C}\right)$ & $\mathrm{W} /(\mathrm{mK})$ & 117 \\
\hline & & $\begin{array}{c}\mathrm{Al}: 92,4-95,6 \\
\mathrm{Mg}: 4,0-4,9 \\
\mathrm{Cr}: 0,05-0,25\end{array}$ \\
\hline Kimyasal bileşim & $\%$ &
\end{tabular}




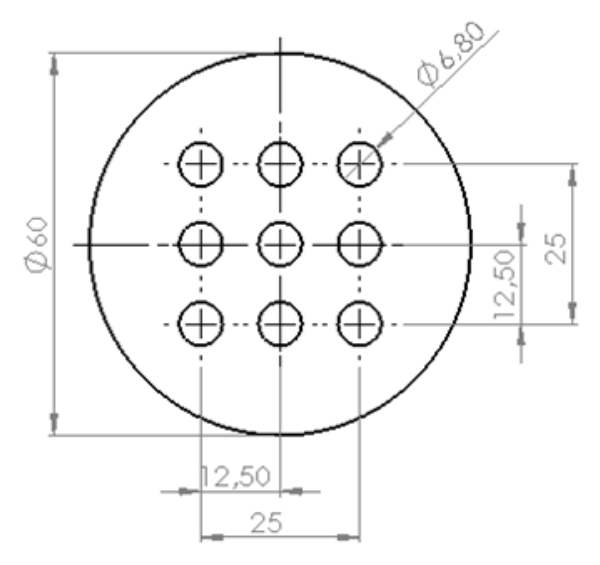

Şekil 1. Delik koordinatları (Hole coordinates)

Tablo 2. Kılavuz çekme parametreleri ve değerleri (Tapping parameters and values)

\begin{tabular}{|c|c|c|c|}
\hline Parametre & \multicolumn{3}{|c|}{ Değer } \\
\hline Kilavuz geometrisi (K) & 1 & 2 & 3 \\
\hline Kesme hızı (m/dk.) & 2 & 4 & 8 \\
\hline
\end{tabular}

Tablo 3. HSS kılavuzların özellikleri (Properties of HSS taps)

\begin{tabular}{|c|c|c|c|}
\hline $\begin{array}{c}\text { Kılavuz } \\
\text { kodu } \\
\text { (K) }\end{array}$ & Kodu & $\begin{array}{c}\text { Teknik } \\
\text { özellikler }\end{array}$ & Resim \\
\hline K:1 & $\begin{array}{c}\text { MTE } \\
\text { B00105 } \\
720800\end{array}$ & $\begin{array}{c}\text { Düz kanallı } \\
\text { makina } \\
\text { k1lavuzu }\end{array}$ & \\
\hline K:2 & $\begin{array}{c}\text { MTE } \\
\text { B00105 }\end{array}$ & $\begin{array}{c}\text { Eğik ağız } \\
\text { bilemeli } \\
\text { makina } \\
\text { k1lavuzu }\end{array}$ & \\
\hline K:3 & MTE & $\begin{array}{c}\text { Helis } \\
\text { kanallı } \\
\text { makina } \\
\text { k1lavuzu }\end{array}$ & \\
\hline & 790105 & \\
\hline
\end{tabular}

Vida açılan delikler eksenleri doğrultusunda GF CUT 300 SP tel erezyon tezgâhında kesilmiş, kesilen yüzeylerden stereo mikroskop ile fotoğraflar çekilerek görüntüler alınmıştır. Alınan görüntülerden AutoCAD yazılımı kullanılarak diş dibi ve diş üstü değerleri ölçülmüştür (Şekil 2).

$18 \mathrm{~mm}$ kalınlığında deney malzemesine $1,25 \mathrm{~mm}$ adımlı yaklaşık 14 adet M8 vida diş profili oluşturulmuş ve ölçümler ortada bulunan 6 dişin ölçülmesi sonucu elde edilen değerlerin ortalamaları alınarak belirlenmiştir. Daha sonra, değeri kesin olarak bilinen (çalışmamızda adım (P=1,25 mm) alınmıştır) uzunluk ile ölçülmek istenen uzunluk (diş üstü ve diş dibi) karşılaştırılmıştır. Standart M8×1,25 diş geometrisinde, adım (P) 1,25 mm, diş dibi (P/8) $0,15625 \mathrm{~mm}$ ve diş üstü $(\mathrm{P} / 4) 0,3125 \mathrm{~mm}$ olmalıdır. Çalışmada somun toleransı olarak $7 \mathrm{H}$ somun tolerans temel alınarak hesaplamalara dâhil edilmiştir. Buna göre M8×1,25 için ortalama vida çapı (böğür çapı) minimum 7,188 mm, maksimum 7,388 $\mathrm{mm}$ aralığında, diş dibi değeri minimum $0,1565 \mathrm{~mm}$ ve maksimum $0,253 \mathrm{~mm}$ aralığında ve diş üstü değeri ise minimum $0,313 \mathrm{~mm}$ maksimum $0,506 \mathrm{~mm}$ aralı̆̆ında olmalidir (Tablo 4).
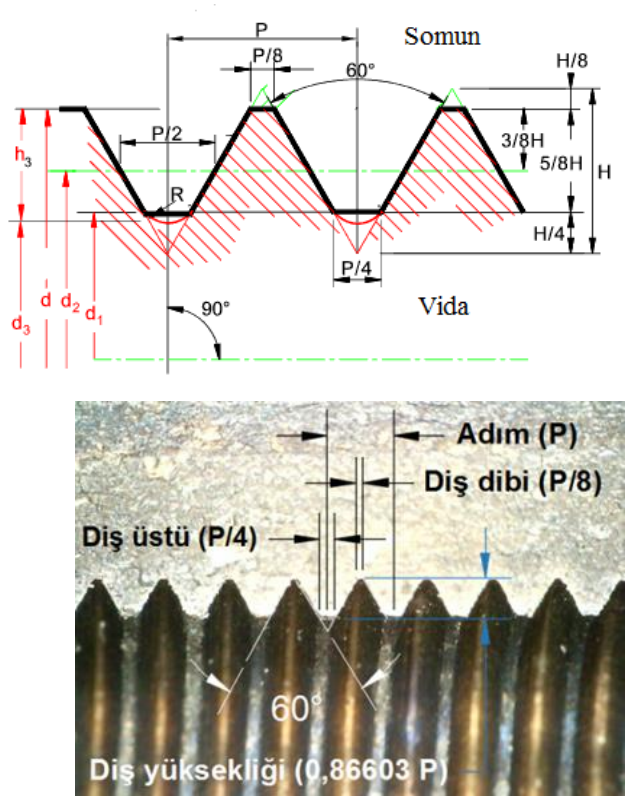

Şekil 2. a) Standart metrik vida ölçüleri ve b) Auto CAD ölçüm noktaları [11] ((a) Standard metric screw dimensions and b) AutoCAD measurement points)

Tablo 4. M8×1,25 7H somun toleransı için minimum ve maksimum DD ve DÜ değerleri (Min. and max. $D D$ and $O U$ values for nut tolerance $M 8 \times 1.257 \mathrm{H}$ )

\begin{tabular}{|c|c|c|c|c|}
\hline & \multicolumn{2}{|c|}{ Diş dibi } & \multicolumn{2}{c|}{ Diş üstü } \\
\hline Teorik M8×1,25 & \multicolumn{2}{|c|}{0,15625} & \multicolumn{2}{c|}{0,3125} \\
\hline & Min. & Mak. & Min. & Mak. \\
\hline 7H M8×1,25 & 0,1565 & 0,253 & 0,313 & 0,506 \\
\hline
\end{tabular}

\section{BULGULAR VE TARTIŞMA (RESULTS AND DISCUSSION)}

Deneyler sonucunda oluşan dişlere ait DD, DÜ ve hesaplanan standart değerden farkları Tablo 5'te verilmiştir. Ayrıca Şekil 3'te diş profillerinin optik mikroskopla çekilen görüntüleri deney sırasına göre verilmiştir. DD ve DÜ için standart değerlere (DD: $0,15625 \mathrm{~mm}$ ve DÜ: $0,3125 \mathrm{~mm}$ ) en yakın sonuç 3 numaralı kılavuz ile $2 \mathrm{~m} / \mathrm{dk}$. kesme hızında elde edilirken, 1 numaralı kılavuzla $8 \mathrm{~m} / \mathrm{dk}$. kesme hızında çekilen vidalarda DD ve DÜ standart değerlerinden nispeten uzaklaşılmıştır. 
Tablo 5. Deneyler sonucunda ölçülen DD, DÜ değerleri ve standart değerden farkları $(D D, D U$ values measured as a result of the experiments and their differences from the standard value)

\begin{tabular}{|c|c|c|c|c|c|c|}
\hline $\begin{array}{c}\text { Deney } \\
\text { no }\end{array}$ & $\begin{array}{c}\mathrm{Vc} \\
(\mathrm{m} / \mathrm{dk} .)\end{array}$ & $\mathrm{K}$ & $\begin{array}{c}\mathrm{DD} \\
(\mathrm{mm})\end{array}$ & $\begin{array}{l}\text { Standart } \\
\text { değerden } \\
\text { fark1 } \\
(\mathrm{mm})\end{array}$ & $\begin{array}{c}\text { DÜ } \\
(\mathrm{mm})\end{array}$ & $\begin{array}{c}\text { Standart } \\
\text { değerden } \\
\text { fark1 } \\
(\mathrm{mm}) \\
\end{array}$ \\
\hline 1 & 2 & \multirow{3}{*}{1} & 0,165 & 0,0085 & 0,347 & 0,0348 \\
\hline 2 & 4 & & 0,167 & 0,0105 & 0,359 & 0,0464 \\
\hline 3 & 8 & & $0,173^{* *}$ & $0,0163^{* *}$ & $0,377^{* *}$ & $0,0645^{* *}$ \\
\hline 4 & 2 & \multirow{3}{*}{2} & 0,164 & 0,0082 & 0,341 & 0,0284 \\
\hline 5 & 4 & & 0,166 & 0,0102 & 0,351 & 0,0387 \\
\hline 6 & 8 & & 0,171 & 0,0143 & 0,358 & 0,0452 \\
\hline 7 & 2 & \multirow{3}{*}{3} & $0,161^{*}$ & $0,0044^{*}$ & $0,323^{*}$ & $0,0103^{*}$ \\
\hline 8 & 4 & & 0,162 & 0,0061 & 0,325 & 0,0129 \\
\hline 9 & 8 & & 0,163 & 0,0068 & 0,331 & 0,0181 \\
\hline
\end{tabular}

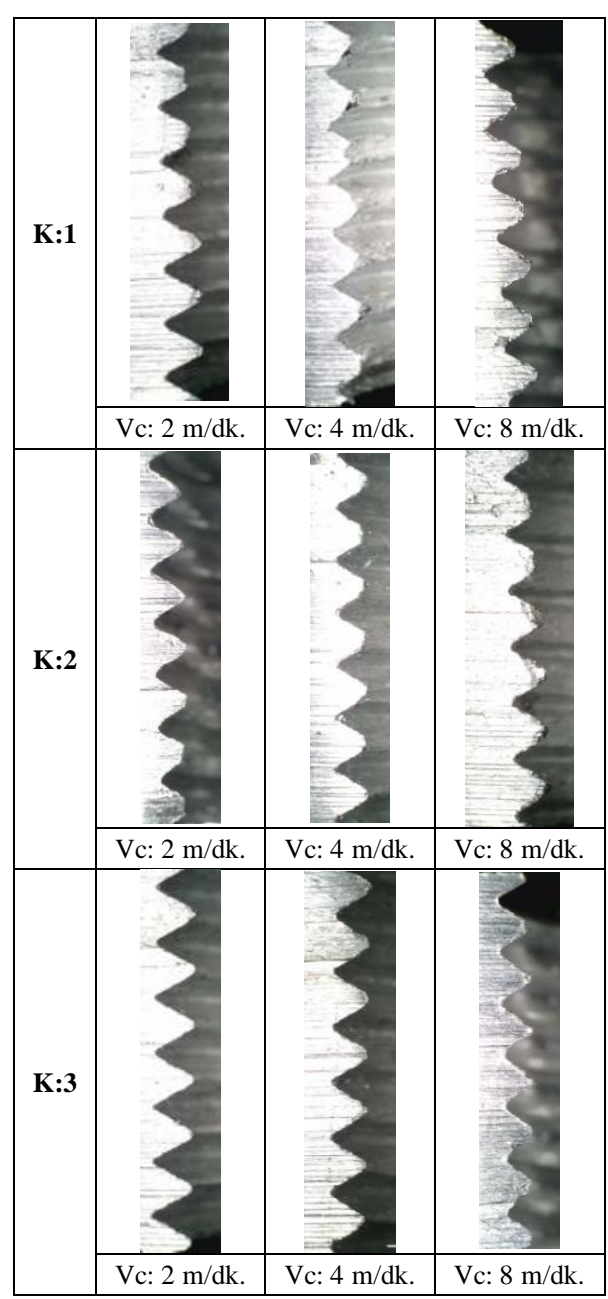

Şekil 3. Deney sonucunda oluşan vida dişi profilleri (Thread profiles formed as a result of the experiment)

Şekil 4 a ve b'de kesme hızına bağlı DD ve DÜ değerlerindeki değişimler, Şekil 5 a ve b'de ise kılavuz profiline bağlı DD ve DÜ değerlerindeki değişimler grafikler yardımıyla gösterilmiştir. Şekil 4 incelendiğinde 3 numaralı helis açılı kılavuz ile standartlara en yakın diş profillerinin elde edilebileceği söylenebilir. Ayrıca kesme hızının artan değerleri diş profillerini standart ölçülerden (DD: $0,15625 \mathrm{~mm}$ ve DÜ: $0,3125 \mathrm{~mm}$ ) uzaklaştırdığı görülmektedir. 3 numaralı helis açılı kılavuz ile en düşük kesme hızı olan $2 \mathrm{~m} / \mathrm{dk}$.'da standart diş profilleri için en yakın değerlere ulaşılmıştır.

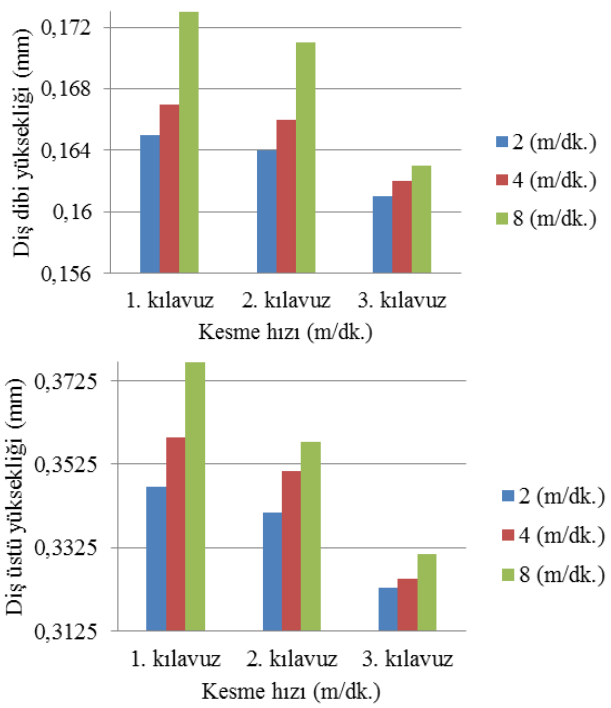

Şekil 4. Kesme hızına bağlı DD ve DÜ değerlerindeki değişimler a)DD ve b)DÜ (Changes in DD and DÜ values depending on the cutting speed a) DD and b) DÜ)

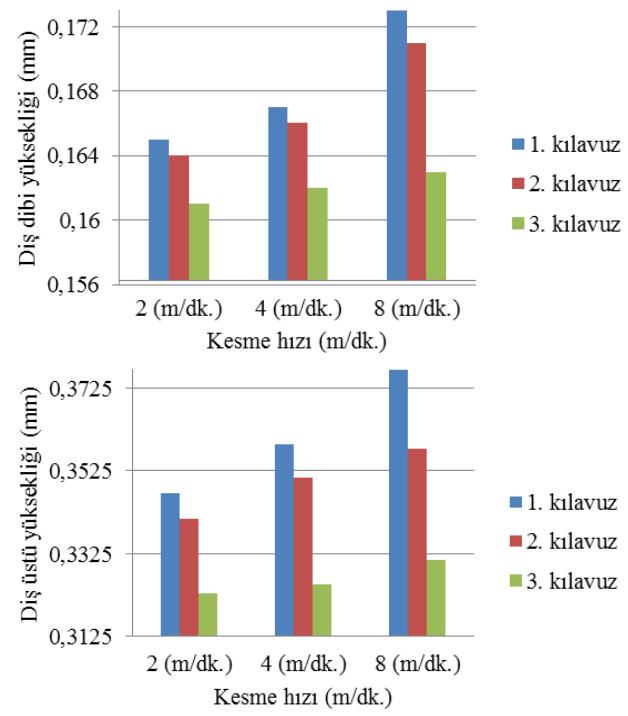

(a)

Şekil 5. Kılavuz profiline bağlı DD ve DÜ değerlerindeki değişimler a)DD ve b)DÜ (Changes in $D D$ and $D U ̈$ values depending on the taps geometries $a) D D$ and $b$ ) $D \ddot{U})$

Şekil 6'da deliklere kılavuzla vida açılması sonucu kılavuzların delik çıkışlarında (vida sonunda) 
kılavuzdan kaynaklanan çapak oluşumlarının görüntüleri verilmiştir. Şekil incelendiğinde helis kılavuzla vida sonlarında çapak oluşumunun diğer kılavuzlara nazaran azaldığı görülmektedir. Ayrıca çapak oluşumu üzerinde kesme hızı da etkilidir. Kesme hızının düşük değerlerinde nispeten çapak oluşumu azalma eğilimine girmiştir. Şekil 7'de 3 farklı kılavuzla vida çekme sonucu oluşan talaşlar görüntülenmiştir. Şekilde düz kılavuzlarda talaş oluşumunun kısa ve nispeten küçük olduğu, helis kılavuzda ise talaşların spiral şeklinde ve nispeten uzun oluştuğu görülmektedir.

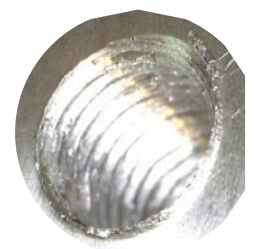

$\mathrm{K}: 1$

$\mathrm{Vc} ; 2 \mathrm{~m} / \mathrm{dk}$.

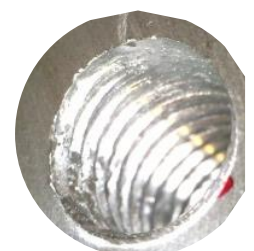

$\mathrm{K}: 2$

$\mathrm{Vc} ; 2 \mathrm{~m} / \mathrm{dk}$.

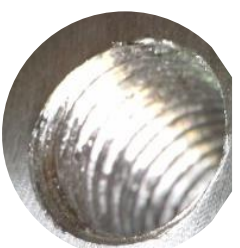

$\mathrm{K}: 3$

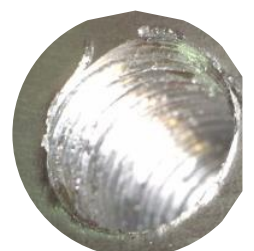

$\mathrm{K}: 1$

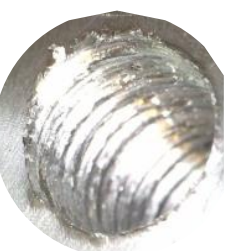

$\mathrm{K}: 1$
$\mathrm{Vc} ; 4 \mathrm{~m} / \mathrm{dk}$.

$\mathrm{Vc} ; 8 \mathrm{~m} / \mathrm{dk}$.

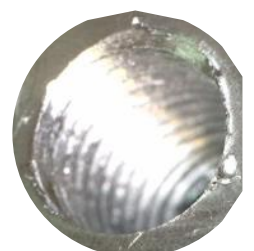

$\mathrm{K}: 2$

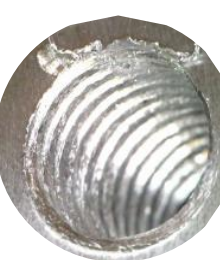

$\mathrm{K}: 2$

$\mathrm{Vc} ; 8 \mathrm{~m} / \mathrm{dk}$.

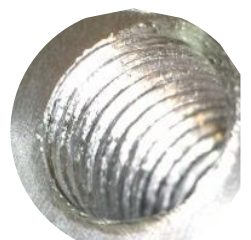

$\mathrm{K}: 3$

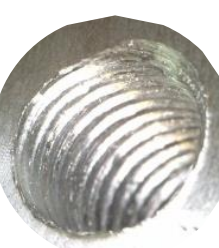

$\mathrm{K}: 3$
Vc; $2 \mathrm{~m} / \mathrm{dk}$. Vc; $4 \mathrm{~m} / \mathrm{dk} . \quad \mathrm{Vc} ; 8 \mathrm{~m} / \mathrm{dk}$.

Şekil 6. Vida açma sonucunda vida sonlarında oluşan çapaklar (Burrs at the screw ends as a result of tapping)

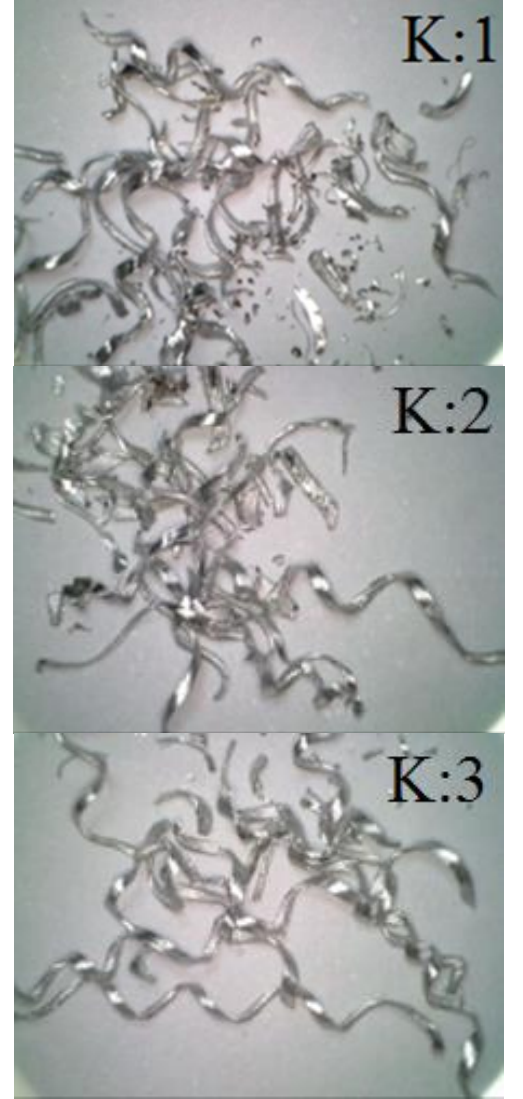

Şekil 7. Kılavuz geometrisine bağlı oluşan talaşlar (Chips formed due to tap geometry)

\section{SONUÇLAR (CONCLUSION)}

A15083 H114 alaşımının 3 farklı kesme hızı ve 3 farklı geometriye sahip kılavuzlarla vida çekme işlemi uygulanmıştır. Kesme sıvısı kullanılmadan gerçekleştirilen deneylerde oluşan dişlere ait diş dibi ve diş üstü değerleri mukayese edilmiştir. Deneyler sonucunda aşağıdaki çıkarımlar elde edilmiştir.

- DD ve DÜ için standart değerlere en yakın sonuç 3 numaralı kılavuz ile $2 \mathrm{~m} / \mathrm{dk}$. kesme hızında elde edilmiştir.

- 1 numaralı kılavuzla $8 \mathrm{~m} / \mathrm{dk}$. kesme hızında çekilen vidalarda DD ve DÜ standart değerlerinden nispeten uzaklaşılmıştır.

- Kesme hızının artan değerleri diş geometrisini olumsuz yönde etkilemiştir.

- Vida sonlarında çapak oluşumu helis kılavuzlarda nispeten azalmaktadır. Ayrica helis kılavuzlarda talaşlar spiral şeklinde ve nispeten uzun oluşmaktadır.

\section{TEŞEKKÜR (ACKNOWLEDGEMENT)}

$\mathrm{Bu}$ çalışma Çankırı Karatekin Üniversitesi Bilimsel Araştırma Projesi Birimi (MYO801202B32) 
tarafindan desteklenmiştir. Kuruma desteklerinden ötürü teşekkür ederiz.

\section{ÇIKAR ÇATIŞMASI BEYANI (CONFLICT OF INTEREST STATEMENT)}

Yazarlar tarafindan herhangi bir çıkar çatışması bildirilmemiştir.

\section{KAYNAKLAR (REFERENCES)}

[1] K. Güleryüz and R. Kaçar, "Effect of Deformation Ageing in The Mechanical Properties of AA 7075 Aluminium Alloy," in 6th International Advanced Technologies Symposium, IATS11, Elazığ, Turkey, May 16-18 2011, pp. 147-152.

[2] A. Çakır, O. Bahtiyar and U. Şeker, "Farklı soğutma şartları ile farklı kesme parametrelerinin AA7075 ve AA2024 alüminyum alaşımlarında delik delme işlemlerine etkisinin deneysel olarak incelenmesi," in 16th International Conference on Machine Design and Production, Izmir, Turkey, June 30 - July 03 2014, pp. 1396.

[3] Z. Demir, “A7075-T651 alüminyum alaşımının ve St37 çelik malzemesinin sürtünmeli delme yöntemi ile delinmesinin deneysel incelenmesi," Ph.D. dissertation, Firat University Institute of Science and Technology, Elazı ̌̆, Turkey, 2012.

[4] N. Fridlyander, V. G. Sister, O. E.Grushko, V. V. Berstenev, L. M. Sheveleva and L. A. Ivanova1, "Aluminum alloys: Promising materials in the automotive industry," Metal Science and Heat Treatment, Translated from Metallovedeniei Termicheskaya Obrabotka Metallov, vol. 9, pp. 3-9, 2002.

[5] G. Uzun and İ. Korkut, "The effect of cryogenic treatment on tapping," The International Journal of Advanced Manufacturing Technology, vol. 67, pp. 857-864, 2013.

[6] M. Nalbant, M. Günay and Y. Yıldız, "Modelling of the effect of different infeed angles and cutting areas on the cutting forces in external threading," Turkish J. Eng. Env. Sci., vol. 32, pp. 153-161, 2008.

[7] M. Günay, "Investigation of the effects on screw thread of infeed angle during external threading," Gazi University Journal of Science, vol. 24:1, pp. 153160, 2011.

[8] G. Uzun and İ. Korkut, "The experimental investigation of cutting forms in tapping of Ti6Al4V alloys," in International Iron \& Steel Symposium, Karabük, Türkiye, Apr 02-04 2012, pp. 870-876.

[9] Y. Kayır, "The effect of hole diameter on cutting forces for tapping on an AA5083 alloy," J. Fac. Eng. Arch. Gazi Univ., vol. 25:4, pp. 671-679, 2010.

[10] G. Uzun ve İ. Korkut, "Kılavuz ile vida açma işlemine kesme yönteminin ve kesme parametrelerinin etkileri," 3. Ulusal Talaşlı Imalat Sempozyumu, Ankara, Türkiye, 2012, pp. 4-5.

[11] H. Gökçe and M. Yavuz, "The effect of cutting speed in tapping process with commercial purity molybdenum material HSS tap," Gazi Journal of Engineering Sciences (GJES), vol. 5:3, pp. 237-243, 2019.

[12] A. E. Reiter, B. Brunner, M. Ante and J. Rechberger, "Investigation of several PVD coatings for blind hole tappingin austenitic stainless steel," Surface \& Coatings Technology, vol. 200, pp. 55325541, 2006.

[13] M. Jin, S. Watanabe, S. Miyake and M. Murakawa, "Trial fabrication and cutting performance of CBN coated taps," Surface and Coatings Technology, vol. 133-134, pp. 443-447, 2000.

[14] Material Property Data, [Online]. http://www.matweb.com/search/DataSheet.aspx?Mat GUID=1efe 7441a72f4a22a53c0dc1bd9c87ec\&ckck= 1. [Accessed: november 18, 2020].

\section{Hüseyin GÖKÇE}

Hüseyin GÖKÇE 1982 yılında Çankırı'da doğdu; ilk, orta ve lise öğrenimini Konya'da tamamladı. 2005 yılında Gazi Üniversitesi Teknik Eğitim Fakültesi Makine Eğitimi Bölümü'nden mezun olmuş, 2007 yılında Selçuk Üniversitesi Endüstri Mühendisliği bölümünde yüksek lisansını bitirmiş ve aynı yıl Ankara'da askerlik görevini tamamlamıştır. 2018 yılında Karabük Üniversitesi İmalat Mühendisliği alanında Doktora derecesi almıştır. Otomotiv yedek parça üretimi, dökümhane otomasyon sistemleri, CNC-CAD-CAM sistemleri konularında özel sektör tecrübesi olan Gökçe, 2009 yılında Çankırı Karatekin Üniversitesi'nde göreve başlamış ve halen aynı kurumda Makine Mühendisliği bölümünde Dr. Öğr. Üyesi olarak görevine devam etmektedir. Evli ve bir çocuk babasıdır. 